\title{
Function of cGMP-dependent protein kinase II in volume expansion-induced diuresis
}

\author{
Andrea Schramm*, Elisabeth Schinner, Jens Schlossmann \\ From 6th International Conference on cGMP: Generators, Effectors and Therapeutic Implications \\ Erfurt, Germany. 28-30 June 2013
}

\section{Background}

The field of cGMP/cGKII-mediated mechanisms regarding kidney function is rather unexplored. ANP, as the major upstream regulator of cGKII, is known to cause diuresis and natriuresis by renal vascular as well as direct tubular effects. The collecting duct (CD) is thought to be the main target site of ANP in the kidney; an inhibition of $\mathrm{Na}^{+}$- reabsorption was shown for outer and inner medullary CD [1-3]. In contrast, the effect of ANP on fluid reabsorption in $\mathrm{CD}$ is discussed very controversially. Short-term regulation of Aquaporin 2 (AQP2), the predominant apical water channel in the $\mathrm{CD}$, occurs mainly via membrane insertion/excision. Stimulation as well as inhibition of AQP2-trafficking upon ANP-administration have been reported $[4,5]$. However, the downstream effectors of ANP regarding fluid- and ion-absorption have not been elucidated so far.

\section{Results}

We investigated if renal parameters in different conditions (basal, salt diets, water load) are dependent on cGKII by using a genetically modified mouse model (cGKII-KO). We could not detect any differences between WT and cGKII-KO during basal conditions, except for a slightly decreased urine output and a significantly lowered amount of creatinine in urine during a normal salt diet.

When mice are subjected to a volume expansion (performed by application of a $10 \mathrm{mM}$ glucose-solution (3\% of $B W$ ) via feeding needle), WT mice exhibit a potent diuresis. In contrast, urine volume is decreased significantly in cGKII-KO. Furthermore, $\mathrm{Na}^{+}$-excretion is also significantly lowered in cGKII-KO. This effect can be abolished by similar administration of Amiloride.

\section{Conclusion}

During different salt loads, cGKII is proposed to be involved only to a minor extent in regulating the renal concentration ability. In contrast, cGKII-KO mice are not able to handle an acute volume load. Our results suggest that membrane insertion of AQP2 is inhibited by cGMP/cGKII. Furthermore, we could eludicate that cGKII is an important regulator of sodium reabsorption by $\mathrm{ENaC}$.

\section{Acknowledgement}

This work was supported by grants from the DFG SFB 699

\section{Published: 29 August 2013}

\section{References}

1. Nonoguchi $\mathrm{H}$, Sands JM, Knepper MA: ANF inhibits $\mathrm{NaCl}$ and fluid absorption in cortical collecting duct of rat kidney. Am J Physiol - Ren Physiol 1989, 256:F179-F186.

2. Rocha AS, Kudo LH: Atrial peptide and cGMP effects on $\mathrm{NaCl}$ transport in inner medullary collecting duct. Am J Physiol - Ren Physiol 1990, 259: F258-F268.

3. Sonnenberg H, Cupples WA, de Bold AJ, Veress AT: Intrarenal localization of the natriuretic effect of cardiac atrial extract. Can J Physiol Pharmacol 1982, 60:1149-1152.

4. Klokkers J, Langehanenberg P, Kemper B, Kosmeier S, von Bally G, Riethmüller $C$, Wunder $F$, Sindic A, Pavenstädt $H$, Schlatter $E$, Edemir B: Atrial natriuretic peptide and nitric oxide signaling antagonizes vasopressin-mediated water permeability in inner medullary collecting duct cells. Am J Physiol - Ren Physiol 2009, 297:F693-F703.

5. Boone M, Kortenoeven M, Robben JH, Deen PM: Effect of the CGMP pathway on AQP2 expression and translocation: potential implications for nephrogenic diabetes insipidus. Nephrol Dial Transplant 2010, 25:48-54.

doi:10.1186/2050-6511-14-S1-P63

Cite this article as: Schramm et al:: Function of cGMP-dependent protein kinase II in volume expansion-induced diuresis. BMC Pharmacology and Toxicology 2013 14(Suppl 1):P63.

\footnotetext{
* Correspondence: Andrea.Schramm@chemie.uni-regensburg.de Department of Pharmacology and Toxicology,University of Regensburg, Germany
} 